\title{
Phosphodiesterase type 5 inhibitors: back and forward from cardiac indications
}

\author{
C. Corinaldesi ${ }^{1} \cdot$ L. Di Luigi ${ }^{1} \cdot$ A. Lenzi $^{2} \cdot$ C. Crescioli $^{1}$
}

Received: 19 March 2015 / Accepted: 11 June 2015 / Published online: 28 June 2015

(C) The Author(s) 2015. This article is published with open access at Springerlink.com

\begin{abstract}
PDE5 inhibitors (PDE5i) are widely known as treatment for erectile dysfunction (ED). This favorable action has emerged as a "side effect" from pioneering studies when PDE5i have been originally proposed as treatment for coronary artery disease (CAD). PDE5i showed marginal benefits for CAD treatment; although disappointing for that indication, they improved systemic and pulmonary vasodilation and ameliorated general endothelial function. Therefore, PDE5i have been approved and licensed also for pulmonary artery hypertension (PAH), besides ED. Nowadays, fine-tuned biomolecular mechanisms of PDE5i are well recognized to be beneficial onto myocardial contractility and geometry, to reduce tissue fibrosis, hypertrophy and apoptosis. PDE5i consistently exert benefits on heart failure, infarct, cardiomyopathy. The concept that PDE5i likely blunt Th1-driven inflammatory processes, which shift the homeostatic balance from health to disease, has emerged; PDE5i seem to decrease the release of active biomolecules from cells to tissues interested by inflammation. In this view, following clinical and basic research progresses, PDE5i can be undoubtedly "re-allocated" for cardiac indications and, hopefully, they could be approved as therapeutic tools to treat and prevent heart disease. This review aims to summarize PDE5i different clinical applications, from past to present and future, focusing on their potential power as treatment for cardiac diseases.
\end{abstract}

C. Crescioli

clara.crescioli@uniroma4.it

1 Department of Movement, Human and Health Sciences, Section of Health Science, Unit of Endocrinology, University of Rome "Foro Italico", Rome, Italy

2 Department of Experimental Medicine, Sapienza University of Rome, Rome, Italy
Keywords PDE5 inhibitors · Cardioprotection · Inflammation

\section{Introduction}

Phosphodiesterase type 5 inhibitors (PDE5i) are powerful strong vasoactive drugs widely used to treat erectile dysfunction (ED) by the specific inhibition of PDE5 activity. $3^{\prime}, 5^{\prime}$-Cyclic nucleotide phosphodiesterases (PDEs) are ubiquitous catalytic enzymes that cleave the phosphodiester bonds in cyclic adenosine or guanosine monophosphate (cAMP and cGMP) to yield 5'-cyclic nucleotides (5'AMP, $5^{\prime}$ GMP). PDEs are a large family including at least 11 different isozymes (PDE1-PDE11), with highly conserved catalytic domain close to carboxy-terminal portion (C-terminus) $[1,2]$. They share common features, such as protein sequence, structure and enzymatic properties, inhibitor sensitivity $[2,3]$.

The different families of mammalian PDEs are alternatively spliced in a tissue-specific manner and generate mRNAs and proteins with specific different regulatory properties. Multiple PDE isoforms are involved in creating heterogeneous cyclic nucleotide signaling within the cells $[4,5]$. However, albeit some redundancy has been observed in cAMP and cGMP hydrolyzation, selective inhibitory activity has been identified on the basis of structural differences among domains: PDE5, 6 and 9 are specific for cGMP cleavage, whereas PDE4, 7 and 8 are cAMP specific; subtypes $1,2,3,10$ and 11 are enzymatically active on both cyclic isotypes [6,7].

This review aims to offer an overview onto the different clinical applications of PDE5i from past, when first hypothesized for cardiovascular use, to present, mainly dedicated to ED treatment, and future, potentially "renewed" 
as therapeutic tools for cardiomyopathic disturbance and disease.

\section{PDE subfamilies, tissue distribution and function}

PDE1, also known as Calcium and calmodulin dependent phosphodiesterase, is widely distributed in different tissues and cells especially in brain areas and heart [8]. PDE2, which is expressed in various tissues-i.e., adrenal cortex, brain, corpus cavernosum, heart, kidney, liver, visceral smooth muscle and skeletal muscle-hydrolyzes cGMP with higher affinity than cAMP $[8,9]$. PDE3 expression is high in adipocytes, pancreatic $\beta$-cells, platelets and vascular smooth muscle. PDE3 is clinically relevant because it regulates hemodynamic parameters, i.e., increases cardiac output and reduces left and right ventricular filling pressure, through direct enhancement of myocardial contractility [10, 11]. The subfamily of PDE4 enzymes, specific for cAMP, is a therapeutic target for central nervous system since these proteins, expressed especially in the brain, are involved in several processes, such as mood control, emesis and olfactory sensory transduction $[8,9,12]$. PDE6 (photoreceptor PDE) is the best-studied enzyme due to its important role in the signal transduction of light. Like all photoreceptor, it is expressed in the outer segments of the retinal photoreceptor neurons [9]. PDE7 is widely distributed in skeletal muscle and lymphocytes and has high affinity for cAMP but still little is known about its function and regulation $[8,9]$. PDE8 expression has been found particularly in testis, followed by other tissues (eye, liver, skeletal muscle, heart, 7 day embryo, kidney, ovary, and brain) [13]; it seems to be an important modulator for $\mathrm{T}$ effector cell functions and a regulator for $\mathrm{T}$ cell adhesion to vascular endothelium through the cAMP signaling pathway [14]. PDE9 is highly represented in kidney, spleen, lung, brain lymph node and thymus. It controls the activity of atrial natriuretic peptide
(ANP) in excretory functions. PDE10 may be involved in the physiological regulation of motor and cognitive function [15]. Recent findings reveal that PDE11 expression is restricted in hippocampus and subiculum suggesting a potential specific role in mood and cognitive function [16].

After this summarized description of all the main types of PDEs, their localization and specific functions studied up to now, the topic of this paper will be addressed onto PDE5 function and, particularly, inhibition.

\section{PDE5 tissue distribution, cellular expression and subcellular localization}

PDE5 subtype is generated by one specific gene, PDE5A, on chromosome $4 \mathrm{q} 25-27$, with three alternative spliced variants, PDE5A1, 5A2, 5A3, which differ at $5^{\prime}$ ends of mRNA and amine-terminal (N-terminus) [8]. All three human PDE5 isoforms share all known functional features such as phosphorylation site, allosteric cGMP-binding sites, catalytic domain. They also have similar biochemical properties regarding, i.e., cGMP binding, cGMP hydrolysis, and drug sensitivity [17]. PDE5 is present in virtually all cell types, tissue and organs; in particular, in humans PDE5 is expressed in lung, heart, penis, vagina, uterus, brain, prostate, retina and platelets [17-29] with different and numerous functions up to the anatomical district, both in physiological and pathological conditions [17-29]. Concerning the latter ones, the inhibition of PDE5 activity can achieve different favorable effects, and, therefore, different clinical applications could be hypothesized [17-29], i.e., from urogenital diseases to neurodegenerative disorders, besides sexual dysfunction in male and females.

Table 1 summarizes tissue distribution and cell expression of PDE5 together with the possible specific clinical application of PDE5i.

Table 1 Tissue and cell distribution of PDE5. Potential clinical applications of PDE5i are depicted

\begin{tabular}{ll}
\hline Tissue distribution/cell expression & Potential application of PDE5i \\
\hline Heart/cardiomyocytes [21] & $\begin{array}{c}\text { Cardiac dysfunction (heart failure, ischemia/reperfusion injuries, } \\
\text { infarct, ventricular arrhythmias, cardiopulmonary bypass) } \\
\text { Erectile dysfunction }\end{array}$ \\
Penis [17] & $\begin{array}{l}\text { Female sexual dysfunction } \\
\text { Vagina/vessel smooth muscle, endothelial and epithelial cells [18, 22] } \\
\text { Uterus/myometrial cells [19, 22] }\end{array}$ \\
Brain/purkinje cells [24, 25] & Preterm labor \\
Prostate/endothelial and smooth muscle cells [26] & Lower urinary tract symptoms \\
Urethra/ureteral smooth muscle [22] & Ureteral colic \\
Bladder [22] & Overactive bladder symptoms \\
Lung/pulmonary arteries, vascular smooth muscle cells [23] & Pulmonary arterial hypertension \\
Platelets [27] & Anti-platelet agents/inhibition of platelet aggregation \\
Retina/endothelial and smooth muscle cells of retina and choroids & Regulation of ocular blood flow/retinal ischemic disease \\
vessels, ganglion and bipolar cells [28, 29] & \\
\hline
\end{tabular}


As from studies onto subcellular localization and function, PDE5 is mainly expressed and widely distributed in the cytoplasmic cell compartmentin myometrial cells, endothelial cells, smooth muscle cells of corpora cavernosa (CC) and peripheral blood mononuclear cells; in particular, in myometrial and endothelial cells, PDE5 distinct localization and accumulation in discrete vesicular compartment, corresponding to centrosomal area, may account for cGMP regulation during contraction [18-20].

\section{PDE5 and ED}

PDE5 is widely expressed in endothelial and smooth muscle cells in penis corpora cavernosa where this specific subtype is 10-100-fold higher vs. other tissues [30] and specifically catalyzes cGMP.

\section{PDE5 biomolecular mechanism}

Penile erection is promoted by cGMP through vascular smooth muscle cells (VSMC) relaxation mediated by the action of nitric oxide (NO).

NO, released from both nonadrenergic noncholinergic nerve terminals and endothelial cells, diffuses into VSMC and promotes cGMP synthesis [8]. Cellular cGMP level in corpus cavernosum is primarily dictated by the balance between the cGMP synthesis, by guanylyl cyclases, and cGMP shut down, by PDE5. Whenever blood flow is decreased-i.e., due to structural or functional deterioration of the peripheral vascular bed and/or nerves; NO inadequate production by neurons and/or endothelium; cGMP excessive breakdown by PDE5; VSMC decreased compliance-penile connective tissue cGMP elevation may not be adequate to provide for a sufficient degree of penile tumescence, thereby resulting in ED [31, 32]. As PDE5 specific inhibitors block the PDE5 catalytic site, cGMP stabilization and accumulation is enhanced and penile erection achieved $[33,34]$.

\section{PDE5i pharmacokinetics and efficacy}

Sildenafil, vardenafil, tadalafil and avanafil, the commercialized PDE5i, are "competitive inhibitors" with cGMP for access to the catalytic site, but they do not interact with the nonhydrolytic allosteric cGMP-binding sites on PDE5 [35-37].

All PDE5i retain different bioavailability, onset of action and pharmacokinetics profiles.

Plasma half-lives of sildenafil and vardenafil are similar, about $4 \mathrm{~h}$, avanafil half-life is shorter, about $3 \mathrm{~h}$, whereas tadalafil half-life is longer, $17.5 \mathrm{~h}[38,39]$. Sildenafil efficacy of action can last up to $12 \mathrm{~h}$, similarly to vardenafil; tadalafil efficacy is maintained for up to $36 \mathrm{~h}$, while avanafil has the shorter period of efficacy, with a maximal duration of action of $6 \mathrm{~h}[40,41]$.

Those PDE5i reach the highest concentrations in plasma $\left(T_{\max }\right)$ with different times. $T_{\max }$ of 30-45 min for avanafil after dosing, indicating a rapid diffusion into the bloodstream when administered orally [42]; $T_{\max }$ values of $60 \mathrm{~min}$ for sildenafil, vardenafil and $120 \mathrm{~min}$ for tadalafil [38]. All enzymes differ for $50 \%$ inhibitory concentration $\left(\mathrm{IC}_{50}\right): 4 \mathrm{nM}$ sildenafil, $0.1-$ $0.4 \mathrm{nM}$ vardenafil, $2 \mathrm{nM}$ tadalafil and 4.3-5.2 $\mathrm{nM}$ avanafil [42]. Similar side effects are reported for all PDE5i, such as headache (10-16\%), flushing (5-12\%), dyspepsia (4-12 \%), nasal congestion (1-10\%), and dizziness (2-3\%) [43].

It is generally accepted that those differences in pharmacokinetics could represent an advantage to choose and adjust the therapy on the basis of patient profile, interaction with some other $\operatorname{drug}(\mathrm{s})$ and evaluation of other aspects and components, either organic or psychic [44, 45]. However, the pharmacological properties and pharmacodynamic features per se have been considered to be criteria not enough sufficient to establish a complete evaluation on PDE5i clinical efficacy: subjective parameters, such as psychometry, patient's preference, life quality or sexual life quality, also have to be included for a complete judgement on the effectiveness of this class of drugs [46]. Of interest, a good correlation between subjective parameters and objective biological measurements has been shown [45, 46]. On the basis of psychometric- and pharmacologic-related parameters, all three PDE5i sildenafil, tadalafil and vardenafil have been defined "harmonious" as they enable penile erection in presence of sexual desire and attractiveness, as extensively reported [46]. Correlating their relative "harmony" with pharmacokinetics helped to measure clinical therapeutic outcome: no substantial dissimilarities have been found among the three molecules. The few differences existing, i.e., between sildenafil, tadalafil and vardenafil pharmacokinetics, make tadalafil - with a longer half-life - superior in number of sexual intercourse per pill, while vardenafil and sildenafil seem preferable when duration of erection, or vascular efficacy and penile hardness are examined [46, 47].

So far, PDE5i have been demonstrated to retain a high specificity of action for ED treatment with an almost perfect tolerance profile.

\section{PDE5i and coronary artery disease}

Albeit now widely used and specifically licensed for ED, the first clinical target of PDE5 inhibition, in pioneering researches, was angina pectoris, in view of the specific isozyme activity and expression in smooth muscle cells and platelets, where PDE5 inhibition reduces aggregation [48]. The specific PDE5i sildenafil citrate, discovered in 1989, was proposed for the treatment of coronary artery 
disease (CAD) [49]. Those initial studies on sildenafil demonstrated only marginal benefits due to little cardiovascular impact, although disappointing for CAD treatment, revealed interesting side effects in male subjects, as penile erection enhancement. Thereafter, further studies for this specific application led, in 1998, to the approval of sildenafil for ED treatment by the US Food and Drug Administration (FDA) [49]. As previously addressed, after sildenafil, other PDE5i, tadalafil (2003), vardenafil (2003) and, recently, avanafil (2012) have been developed and approved for ED treatment by FDA [50].

So far, for quite a long time, the use of PDE5i has been shifted away from cardiovascular applications, and it took nearly a decade after sildenafil first clinical introduction to "reallocate" this class of drugs for cardiovascular disorder treatment [48]. As previously stated, PDE5 expression is, indeed, largely diffuse in several types of tissues and cells connected with cardiovascular function, such as systemic arteries and veins, pulmonary arteries, cardiac and skeletal cells, platelets [21, 51-54].

Hence, basic and clinical studies started to focus onto vasoactive effects in tissues other than urological ones.

\section{PDE5i and pulmonary arterial hypertension}

Due to PDE5 high expression in lung vasculature, several lines of research started to investigate the effect of PDE5 inhibition in pulmonary vascular endothelium and airway epithelium, in pulmonary arterial hypertension (PAH). $\mathrm{PAH}$ development and progression are strictly associated with endothelial dysfunction, vascular remodeling and fibrosis, finally leading to right heart failure. PDE5 upregulation has been documented in remodeled pulmonary artery during PAH [55] and, interestingly, PDE5 inhibition has been shown to ameliorate pulmonary artery systolic and mean artery pressure, dyspnea score and gas transfer, pulmonary vascular resistance and cardiac output, [56, 57].

It seems that circulating endothelial progenitor cell (EPC) is reduced in PAH patients [58, 59]. Remarkably, the treatment with sildenafil dose dependently rises EPC number [59]. Sildenafil-induced improvement in EPC number together with cGMP level stabilization is associated with lower mean pulmonary arterial pressure and higher cardiac index in PAH patients. Furthermore, the major vascular lesions in PAH are associated with abnormal proliferation of VSMC, involved in the pathogenesis of intimal hyperplasia. As from in vitro experiments, sildenafil prevents the proliferation and increases the apoptosis of pulmonary artery smooth cells [55]. This effect seems specific for this cellular target since in other cell types as cardiomyocytes or skeletal muscle cells PDE5 inhibition exert an anti-apoptotic effect involving $\mathrm{Bcl} / \mathrm{Bax}$ signaling [60-62].

Given the improvement of several hemodynamic and clinical parameters following PDE5 inhibition, sildenafil, in 2005, and, thereafter, tadalafil have been approved by the US FDA and became first-line therapies for PAH [63], primary or secondary to other connective tissue diseases, such as scleroderma ( $\mathrm{SSc}$ ) or systemic lupus erythematosus (SLE) - which share identical pathological changes in pulmonary vessels [55].

\section{PDE5i and cardiomyopathies}

Remarkably, in addition to the favorable actions onto PAH, PDE5 inhibition exerts cardioprotective effects as documented in different cardiac pathologies: from heart failure (HF), where sildenafil improves cardiac kinetics [64], to ischemia/reperfusion injuries, where it ameliorates vascular perfusion/density and tissue blood flow, to infarct, where it reduces damage size, apoptotic processes and cardiac hypertrophy, to ventricular arrhythmias, where it reduces disease severity, to cardiopulmonary bypass, where it increases coronary blood flow and cardiac recovery $[3,60$, 61, 63].

Heart protection accomplishment by PDE5i is mainly attributed to the induced vasoactive effects linked to vascular tone regulation and release of endogenous cardioprotective molecules, such as adenosine, bradykinin and phenylephrine from endothelial cells $[6,60]$. This process is related to intracellular protein kinase (PK)C/ERK activation that, in turn, triggers a signaling cascade ending in endothelial/ inducible NO synthase (eNOS/iNOS) phosphorylation and NO release; following cGMP formation and stabilization, PGK activity is enhanced and results in opening $\mathrm{K}_{\mathrm{ATP}}$ channel directly in mitochondria of cardiomyocytes [6]. A direct intramyocardial action of PDE5 inhibition seems to be suggested also by the results obtained in diabetic dilative cardiomyopathy after three-month treatment with $100 \mathrm{mg} / \mathrm{day}$ sildenafil: cardiac geometry and kinetics improved together with a decrease in circulating monocyte chemoattractant protein (MCP)-1 and tumor growth factor (TGF)- $\beta$, independently of any other vasodilatory or endothelial effects [65].

\section{PDE5i and tissue fibrosis}

So far, it could be suggested that sildenafil efficacy in cardioprotection likely relies not only on vasodilation but seems, somehow, a direct effect maybe due to PDE5iinduced antifibrotic action. The latter, in fact, seems to be related to a counter-regulation of the cytokine TGF$\beta$, which is considered an essential molecule for pathogenic stromal reorganization ending in tissue fibrosis. A 
deregulated TGF- $\beta$ signaling is one of the driving events culminating to an altered tissue architecture reorganization [66]. Some cytokines, indeed, like MCP-1, interleukin (IL)- 6 and TGF- $\beta$ exert, either directly or indirectly, a decontrolled extracellular matrix (ECM) assessment and deposition, an altered fibroblast function and protein production-i.e., collagens, fibronectins or proteoglycans [67] - although the underlying mechanisms are part of a very complex network, not yet fully clarified. Furthermore, in vivo studies on fibrotic autoimmune diseases show that sildenafil exerts antifibrotic effects by inhibition of Rho kinase, a key effector for myofibroblast differentiation [68]. Those observations are in line with the ability of the PDE5i vardenafil to inhibit and reverse the trans-differentiation of primary human prostatic cells to myofibroblasts, that is reported to be associated with prostate stromal remodeling and lower urinary tract symptoms (LUTS) in gland hyperplasia $[69,70]$. In view of those effects, the use of sildenafil is also indicated to treat digital ischemic ulcers in Raynaud's phenomenon secondary to SSc since it decreases frequency and duration of digital vasospasms attacks-although not specifically licensed for this indication [71, 72].

Fibrosis, as well known, is a "final" process resulting from the integration of vasculopathic/immunological processes and complex cell-cell dialogue, involving, as addressed before, several active mediators and cytokines responsible for the altered ECM deposition and hypertrophy. Several lines of investigation, i.e., have documented that cardiac fibrosis development derives from a tight interaction between cardiac fibroblasts and cardiomyocytes, via direct contacts or, indirectly, via paracrine factors [73, 74]. This observation is in line with the emerging concept that cardiomyocytes and their complex communications with other nonmyocytes (from fibroblasts to endothelial or immune cells) play a pivotal role in heart pathogenesis and cardiomyopathy development [73-76].

Furthermore, based on data deriving from clinical to basic research, the central role of cardiac cells is likely particularly relevant since the early stages of cardiac diseases and not limited, i.e., to the final histopathological manifestations, such as tissue fibrosis.

The model that sees cardiomyocytes as dynamically active cells and not simply passive targets in cardiomyopathy is well in line with the emerging hypothesis that pathogenesis of heart disease (but not only) derives from the perturbation of healthy conditions by immune/inflammatory events.

\section{PDE5i and Th1-driven inflammation}

Nowadays, inflammation has been recognized as the common link occurring at the onset of several disorders affecting different tissues, including cardiac one. Growing evidence shows that the homeostatic balance between health and disease largely depends on the immune/inflammatory status and the associated biomolecular mediators. Since quite ago, it is known that anti-inflammatory agents may have clinical benefits in preventing cardiovascular disease, in view of the direct relation existing between markers of a general inflammatory status, like C-reactive protein, and the risk of cardiovascular diseases [77].

As research progresses, new evidences emerge on the pivotal role in cardiomyopathy initiation of fine-tuned immune processes, especially driven by pro-inflammatory T helper type 1 cells (Th1) and Th1 type-related molecules and cytokines. Those mechanisms and mediators have been depicted as important triggers for disease development at very early stages, when clinical signs are still not manifested. Thus, early changes of these specific immunoactive/inflammatory molecules, detected either in peripheral blood or at tissue level, could potentially mirror a shift from healthy to disease condition at time of disease onset or even before disease initiation. In this view, we have previously reported on the critical role of the highly chemoattractant cytokine, or chemokine, interferon (IFN) $\gamma$-induced $10 \mathrm{kDa}$ protein, IP-10/ CXCL10 (C-X-C motif chemokine 10), in very early immune processes which elicit the inflammatory cascade, eventually culminating in cardiac homeostasis disturbance [78-80].

Chemokines are, indeed, a family of potent chemotactic small peptides known to drive and control leukocyte trafficking during inflammatory conditions underlying several allo- and autoimmune disease [80, 81]. CXCL10, as the other CXC chemokines induced by IFN $\gamma$ (CXCL9/Mig, or monokine induced by interferon gamma, and CXCL11/ ITAC, or interferon-inducible $\mathrm{T}$ cell alpha chemoattractant) is deeply involved in mechanism(s) committed to initiate and potentiate immune response, such as $\mathrm{T}$ cell priming [82]. Those Th1-related chemokines acting through their specific receptor CXCR3, expressed on T cell surface, retain the capacity to specifically address Th1 cell recruitment to the critical tissue sites going toward alteration induced by inflammation.

Since the pioneering studies, by Hancock et al. on heart transplantation [83], CXCL10 neutralization per se seems enough to improve cardiac function and counteract heart rejection; thereafter, the pivotal role of CXCL10 has been confirmed in human heart transplantation $[78,79,84]$ and recognized in human cardiac function and diseases, from myocarditis to cardiac pulmonary bypass or coronary artery disease [85-87]. Notably, CXCL10 has been proposed as an early pretransplant predictor of organ rejection [78, 84].

In addition, human cardiomyocytes under maximal inflammatory conditions express and secrete CXCL10 besides other factors, i.e., IL-8, IL-6, virtually absent in basal normal conditions $[75,76,86]$. This observation is 
in line with and supports the hypothesis that cardiomyocytes act as active counterparts in inflammation-related dialogue among the different involved districts (systemic/ tissues) and cells (immune/tissue resident cells). Quite remarkably, inflammatory-induced CXCL10 release by human cardiac cells is targeted by some immunesuppressors such as mycophenolate mofetil, or other drugs retaining immunomodulatory activity, such as rosiglitazone or vitamin D receptor agonists $[75,76]$. From our ongoing studies, this inhibitory effect onto CXCL10 release is also observed after the treatment with sildenafil of human cardiomyocytes maximally challenged by inflammation, while no effect has been found in basal condition (personal communication, Di Luigi et al., manuscript under revision, PlosOne 2015). This in vitro observation on the anti-inflammatory effect of PDE5i is consistent with the results obtained from in vivo studies in different pathologies: PDE5i, with PDE4i and PDE7i, seem good candidates as next generation treatments in inflammatory bowel disease [88]; tadalafil and vardenafil are capable to blunt inflammation-induced IL-8 secretion by human myofibroblast prostatic cells (hBPH) [70]; PDE5i attenuate experimental autoimmune encephalomyelitis and experimental arthritis [55].

\section{Conclusions}

Thus, besides rehabilitation of ED, there is growing interest in potential administration of PDE5i in several clinical areas, i.e., from urology, for the relief of symptoms in prostate- and bladder-related disorders, to neurology, due to protection against ischemic injury, respiratory medicine, for the effect on pulmonary hemodynamics, and rheumatology, as treatment for PAH or off-labeled treatment of Raynaud's phenomenon in systemic scleroderma.

When evaluating PDE5i efficacy and clinical outcome in diseases other than sexual disturbance, such as cardiac diseases, to attain a reliable evaluation, several variables have to be taken in account on the basis of the evidence, as previously addressed for ED.

That is to say, while isolated cardiovascular events and sudden deaths have been reported in early studies on PDE5i, successive larger placebo-controlled clinical trials and surveillance studies documented no greater risk of this class of drugs vs. placebo: the detrimental effects were due to the incorrect PDE5i use alongside the nitro compounds (NO-donors) and, thus, contraindication with nitrate use has been assessed. Moreover, studies on effectiveness show a better cardiovascular profile of sildenafil as compared to the other PDE5i [6].

Cardiovascular disease is often concomitant with systemic inflammation and a deregulated status, as previously stated; in this light it is ingruing that sildenafil appears to be effective in un-balanced homeostasis conditions. This observation is consistent with a recent meta-analysis documenting that after sildenafil administration there are no hemodynamic effects in HF subjects with preserved ejection fraction while significant improvements have been achieved in HF patients with reduced ejection fraction [89, 90].

PDE5i seem capable to counteract the release and activity of some biomolecular mediators responsible for eliciting the shift from healthy to disease condition. Those actions are likely to mirror, at least in part, the decrease induced by cGMP stabilization of Th1-related pro-inflammatory activity [55]. Indeed, protein kinase G (PKG) activation by cGMP seems responsible for negative remodeling in HF and cardiac hypertrophy blunting. Nevertheless, PDE5 expression is very low or even undetectable in normal myocardium $[90,91]$ while it is markedly upregulated under inflammation-related processes, such as oxidative stress and pressure overload hypertrophy [92-96].

Overall, PDE5i efficacy in cardiovascular disturbances likely relies on different effects on heart, such as attenuation of adrenergic stimulation, reduction of ventricularvascular stiffening and maladaptive chamber remodeling, improvement of endothelial function and enhancement of renal responsiveness [97]. So far, we could speculate that PDE5i by reverting destabilized homeostatic conditions could exert a general "anti-inflammatory" action which could be potentially associated with clinical favorable outcome.

So far, altogether, those observations might reflect and, in some measure, explain the cardioprotective effects of PDE5i, as found in animal and human studies.

Undoubtedly, other investigations in vivo and in vitro as well are mandatory to confirm the beneficial effects of PDE5i in cardiomyopathies and, possibly, clearly elucidate the underlying biomolecular mechanism(s) as potential pharmacological target(s).

Our ongoing studies are, indeed, toward this direction, and aimed to evaluate PDE5i activity in vivo on circulating level of several Th1-related chemokines, first of all CXCL10, measured in early stages of cardiomyopathies and in vitro on different human cell types, such as endothelial, cardiac and immune cells, to clarify the cellular targets. Of interest, an ongoing randomized, placebo-controlled, double-blind study (ClinicalTrial.gov, NCT01803828) enrolls diabetic females and males to evaluate PDE5i as new anti-remodeling drugs for early diagnosed and genderdependent cardiomyopathy.

Hopefully, once well integrated researches, both at clinical and basic level, will offer strengthened and unambiguous evidence on PDE5i as anti-inflammatory safe therapeutic tools, it is conceivable that this class of drug could 
be licensed for the treatment or even prevention of cardiac diseases.

Open Access This article is distributed under the terms of the Creative Commons Attribution 4.0 International License (http://creativecommons.org/licenses/by/4.0/), which permits unrestricted use, distribution, and reproduction in any medium, provided you give appropriate credit to the original author(s) and the source, provide a link to the Creative Commons license, and indicate if changes were made.

\section{Compliance with ethical standards}

Conflict of interest The authors declare that they have no conflict of interest.

Ethical approval The review summarizes previous studies and does not include human or animal participants.

Informed consent No need for informed consent.

\section{References}

1. Conti M, Beavo J (2007) Biochemistry and physiology of cyclic nucleotide phosphodiesterases: essential components in cyclic nucleotide signaling. Annu Rev Biochem 76:481-511

2. Omori K, Kotera J (2007) Overview of PDEs and their regulation. Circ Res 100:309-327

3. Rao YJ, Xi L (2009) Pivotal effects of phosphodiesterase inhibitors on myocyte contractility and viability in normal and ischemic hearts. Acta Pharmacol Sin 30:1-24

4. Yan C, Miller CL, Abe J (2007) Regulation of phosphodiesterase 3 and inducible cAMP early repressor in the heart. Circ Res 100:489-501

5. Bender AT, Beavo JA (2006) Cyclic nucleotide phosphodiesterases: molecular regulation to clinical use. Pharmacol Rev 58:488-520

6. Kukreja RC, Ockaili R, Salloum F, Yin C, Hawkins J, Das A, Xi L (2004) Cardioprotection with phosphodiesterase-5 inhibition-a novel preconditioning strategy. J Mol Cell Cardiol 36:165-173

7. Rotella DP (2002) Phosphodiesterase 5 inhibitors: current status and potential applications. Nat Rev Drug Discovery 1:674-682

8. Glossmann H, Petrischor G, Bartsch G (1999) Molecular mechanisms of the effects of sildenafil (VIAGRA). Exp Gerontol 34:305-318

9. Beavo JA (1995) Cyclic nucleotide phosphodiesterases: functional implications of multiple isoforms. Physiol Rev 75:725-748

10. Teerlink JR, Metra M, Zacà V, Sabbah HN, Cotter G, Gheorghiade M, Cas LD (2009) Agents with inotropic properties for the management of acute heart failure syndromes. Traditional agents and beyond. Heart Fail Rev 14:243-253

11. Liu H, Maurice DH (1998) Expression of cyclic GMP-inhibited phosphodiesterases $3 \mathrm{~A}$ and $3 \mathrm{~B}$ (PDE3A and PDE3B) in rat tissues: differential subcellular localization and regulated expression by cyclic AMP. Br J Pharmacol 125:1501-1510

12. Gurney ME, D'Amato EC, Burgin AB (2014) Phosphodiesterase-4 (PDE4) molecular pharmacology and alzheimer's disease. Neurotherapeutics 12:49-56

13. Soderling SH, Bayuga SJ, Beavo JA (1998) Cloning and characterization of a cAMP-specific cyclic nucleotide phosphodiesterase. Proc Natl Acad Sci 95:8991-8996

14. Vang AG, Ben-Sasson SZ, Dong H, Kream B, DeNinno MP, Claffey MM, Housley W, Clark RB, Epstein PM, Brocke S (2010) PDE8 regulates rapid Teff cell adhesion and proliferation independent of ICER. PLoS One 5:e12011
15. Siuciak JA (2008) The role of phosphodiesterases in schizophrenia: therapeutic implications. CNS Drugs 22:983-993

16. Kelly MP, Logue SF, Brennan J, Day JP, Lakkaraju S, Jiang L, Zhong X, Tam M, Sukoff Rizzo SJ, Platt BJ, Dwyer JM, Neal S, Pulito VL, Agostino MJ, Grauer SM, Navarra RL, Kelley C, Comery TA, Murrills RJ, Houslay MD, Brandon NJ (2010) Phosphodiesterase 11A in brain is enriched in ventral hippocampus and deletion causes psychiatric disease-related phenotypes. Proc Natl Acad Sci 107:8457-8462

17. Lin CS, Lin G, Xin ZC, Lue TF (2006) Expression, distribution and regulation of phosphodiesterase 5. Curr Pharm Des $12: 3439-3457$

18. D'Amati G, di Gioia CR, Bologna M, Giordano D, Giorgi M, Dolci S, Jannini EA (2002) Type 5 phosphodiesterase expression in the human vagina. Urology 60:191-195

19. Dolci S, Belmonte A, Santone R, Giorgi M, Pellegrini M, Carosa E, Piccione E, Lenzi A, Jannini EA (2006) Subcellular localization and regulation of type-1C and type- 5 phosphodiesterases. Biochem and Biophys Res Commun 341:837-846

20. Carosa E, Castri A, Forcella C, Sebastiani G, Di Sante S, Gravina GL, Ronchi P, Cesarini V, Dolci S, Di Stasi S, Lenzi A, Jannini EA (2014) Platelet-derived growth factor regulation of type-5 phosphodiesterase in human and rat penile smooth muscle cells. J Sex Med 11:1675-1684

21. Lin CS (2004) Tissue expression, distribution, and regulation of PDE5. Int J Impot Res 16:S8-S10

22. Montorsi F, Corbin J, Phillips S (2004) Review of phosphodiesterases in the urogenital system: new directions for therapeutic intervention. J Sex Med 1:322-336

23. Wilkins MR, Wharton J, Grimminger F, Ghofrani HA (2008) Phosphodiesterase inhibitors for the treatment of pulmonary hypertension. Eur Respir J 32:198-209

24. Bender AT, Beavo JA (2004) Specific localized expression of cGMP PDEs in Purkinje neurons and macrophages. Neurochem Int 45:853-857

25. Menniti FS, Faraci WS, Schmidt CJ (2006) Phosphodiesterases in the CNS: targets for drug development. Nat Rev Drug Discov 5:660-670

26. Giuliano F, Ückert S, Maggi M, Birder L, Kissel J, Viktrup L (2013) The mechanism of action of phosphodiesterase type 5 inhibitors in the treatment of lower urinary tract symptoms related to benign prostatic hyperplasia. Eur Urol 63:506-516

27. Gresele P, Momi S, Falcinelli E (2011) Anti-platelet therapy: phosphodiesterase inhibitors. $\mathrm{Br} \mathrm{J}$ Clin Pharmacol 72:634-646

28. Foresta C, Caretta N, Zuccarello D, Poletti A, Biagioli A, Caretti L, Galan A (2008) Expression of the PDE5 enzyme on human retinal tissue: new aspects of PDE5 inhibitors ocular side effects. Eye (Lond) 22:144-149

29. Polak K, Wimpissinger B, Berisha F, Georgopoulos M, Schmetterer L (2003) Effects of sildenafil on retinal blood flow and flicker-induced retinal vasodilatation in healthy subjects. Invest Ophthalmol Vis Sci 44:4872-4876

30. Morelli A, Filippi S, Mancina R, Luconi M, Vignozzi L, Marini M, Orlando C, Vannelli GB, Aversa A, Natali A, Forti G, Giorgi M, Jannini EA, Ledda F, Maggi M (2004) Androgens regulate phosphodiesterase type 5 expression and functional activity in corpora cavernosa. Endocrinology 145:2253-22563

31. Francis SH, Corbin JD (2005) Phosphodiesterase-5 inhibition: the molecular biology of erectile function and dysfunction. Urol Clin North Am 32:419-429

32. Corbin JD, Francis SH (2003) Molecular biology and pharmacology of PDE-5-inhibitor therapy for erectile dysfunction. J Androl 24:S38-S41

33. Corbin JD, Francis SH (2002) Pharmacology of phosphodiesterase-5 inhibitors. Int J Clin Pract 56:453-459 
34. Francis SH, Morris GZ, Corbin JD (2008) Molecular mechanisms that could contribute to prolonged effectiveness of PDE5 inhibitors to improve erectile function. Int J Impot Res 20:333-342

35. Blount MA, Beasley A, Zoraghi R, Sekhar KR, Bessay EP, Francis SH, Corbin JD (2004) Binding of tritiated sildenafil, tadalafil, or vardenafil to the phosphodiesterase-5 catalytic site displays potency, specificity, heterogeneity, and cGMP stimulation. Mol Pharmacol 66:144-152

36. Ballard SA, Gingell CJ, Tang K, Turner LA, Price ME, Naylor AM (1998) Effects of sildenafil on the relaxation of human corpus cavernosum tissue in vitro and on the activities of cyclic nucleotide phosphodiesterase isozymes. J Urol 159:2164-2171

37. Turko IV, Ballard SA, Francis SH, Corbin JD (1999) Inhibition of cyclic GMP-binding cyclic GMP-specific phosphodiesterase (type 5) by sildenafil and related compounds. Mol Pharmacol 56:124-130

38. Katz EG, Tan RB, Rittenberg D, Hellstrom WJ (2014) Avanafil for erectile dysfunction in elderly and younger adults: differential pharmacology and clinical utility. Ther Clin Risk Manag 27:701-711

39. Carson CC (2007) Phosphodiesterase type 5 inhibitors: state of the therapeutic class. Urol Clin North Am 34:507-515

40. Gupta M, Kovar A, Meibohm B (2005) The clinical pharmacokinetics of phosphodiesterase-5 inhibitors for erectile dysfunction. J Clin Pharmacol 45:987-1003

41. Bruzziches R, Francomano D, Gareri P, Lenzi A, Aversa A (2013) An update on pharmacological treatment of erectile dysfunction with phosphodi- esterase type 5 inhibitors. Expert Opin Pharmacother 14:1333-1344

42. Kedia GT, Uckert S, Assadi-Pour F, Kuczyk MA, Albrecht K (2013) Avanafil for the treatment of erectile dysfunction: initial data and clinical key properties. Therapeutic Advances Urol $5: 35-41$

43. Hatzimouratidis K, Hatzichristou DG (2005) A comparative review of the options for treatment of erectile dysfunction: which treatment for which patient? Drugs 65:1621-1650

44. Corona G, Razzoli E, Forti G, Maggi M (2008) The use of phosphodiesterase 5 inhibitors with concomitant medications. J Endocrinol Invest 31:799-808

45. Corona G, Mondaini N, Ungar A, Razzoli E, Rossi A, Fusco F (2011) Phosphodiesterase type 5 (PDE5) inhibitors in erectile dysfunction: the proper drug for the proper patient. J Sex Med 8:3418-3432

46. Jannini EA, DeRogatis LR, Chung E, Brock GB (2012) How to evaluate the efficacy of the phosphodiesterase type 5 inhibitors. $\mathrm{J}$ Sex Med 9:26-33

47. Mirone V, Fusco F, Rossi A, Sicuteri R, Montorsi F (2009) Tadalafil and vardenafil vs. sildenafil: a review of patient-preference studies. BJU Int 103:1212-1217

48. Kass DA, Champion HC, Beavo JA (2007) Phosphodiesterase type 5: expanding roles in cardiovascular regulation. Circ Res 101:1084-1095

49. Chrysant SG, Chrysant GS (2012) The pleiotropic effects of phosphodiesterase 5 inhibitors on function and safety in patients with cardiovascular disease and hypertension. J Clin Hyper 14:644-649

50. Goldstein I, Jones LA, Belkoff LH, Karlin GS, Bowden CH, Peterson CA, Trask BA, Day WW (2012) Avanafil for the treatment of erectile dysfunction: a multicenter, randomized, double-blind study in men with diabetes mellitus. Mayo Clin Proc $87: 843-852$

51. Lugnier C, Schoeffter P, Le Bec A, Strouthou E, Stoclet JC (1986) Selective inhibition of cyclic nucleotide phosphodiesterases of human, bovine and rat aorta. Biochem Pharmacol $35: 1743-1751$
52. Hamet P, Coquil JF, Bousseau-Lafortune S, Franks DJ, Tremblay J (1984) Cyclic GMP binding and phosphodiesterase: implication for platelet function. Adv Cyclic Nucleotide Protein Phosphorylation Res 16:119-136

53. Reffelman T, Kloner RA (2003) Therapeutic potential of phosphodiesterase 5 inhibition for cardiovascular disease. Circulation 108:239-244

54. Senzaki H, Smith CJ, Juang GJ, Isoda T, Mayer SP, Ohler A, Paolocci N, Tomaselli GF, Hare JM, Kass DA (2001) Cardiac phosphodiesterase 5 (cGMP-specific) modulates b-adrenergic signaling in vivo and is down-regulated in heart failure. FASEB J 15:1718-1726

55. Shenoy P, Agarwal V (2010) Phosphodiesterase inhibitors in the management of autoimmune disease. Autoimmun Rev 9:511-515

56. Kukreja RC, Salloum FD, Das A, Kola S, Ockaili RA, Xi L (2011) Emerging new uses of phosphodiesterase-5 inhibitors in cardiovascular diseases. Exp Clini Cardiol 16:e30-e35

57. Mostafa T (2008) Oral phosphodiesterase type 5 inhibitors: nonerectogenic beneficial uses. J Sex Med 5:2502-2518

58. Diller GP, van Eijl S, Okonko DO, Howard LS, Ali O, Thum T, Wort SJ, Bédard E, Gibbs JS, Bauersachs J, Hobbs AJ, Wilkins MR, Gatzoulis MA, Wharton J (2008) Circulating endothelial progenitor cells in patients with Eisenmenger syndrome and idiopathic pulmonary arterial hypertension. Circulation 117:3020-3030

59. Foresta C, De Toni L, Di Mambro A, Garolla A, Ferlin A, Zuccarello D (2008) The PDE5 inhibitor sildenafil increases circulating endothelial progenitor cells and CXCR4 expression. J Sex Med 6:369-372

60. Kukreja RC (2007) Cardiovascular protection with sildenafil following chronic inhibition of nitric oxide synthase. Br J Clin Pharmacol 150:538-540

61. Das A, Xi L, Kukreja RC (2005) Phosphodiesterase-5 inhibitor sildenafil preconditions adult cardiac myocytes against necrosis and apoptosis. Essential role of nitric oxide signaling. J Biol Chem 280:12944-12955

62. Crescioli C, Sturli N, Sottili M, Bonini P, Lenzi A, Di Luigi L (2013) Insulin-like effect of the phosphodiesterase type 5 inhibitor tadalafil onto male human skeletal muscle cells. J Endocrinol Invest 36:1020-1026

63. Schwartz BG, Levine LA, Comstock G, Stecher VJ, Kloner RA (2012) Cardiac uses of phosphodiesterase-5 inhibitors. J Am Coll Cardiol 59:9-15

64. Guazzi M, Vicenzi M, Arena R, Guazzi MD (2011) PDE5 inhibition with sildenafil improves left ventricular diastolic function, cardiac geometry, and clinical status in patients with stable systolic heart failure: results of a 1-year, prospective, randomized, placebo-controlled study. Circ Heart Fail 4:8-17

65. Giannetta E, Isidori AM, Galea N, Carbone I, Mandosi E, Vizza CD, Naro F, Morano S, Fedele F, Lenzi A (2012) Chronic Inhibition of cGMP phosphodiesterase 5A improves diabetic cardiomyopathy: a randomized, controlled clinical trial using magnetic resonance imaging with myocardial tagging. Circ 125:2323-2333

66. Zhao B, Chen YG (2014) Regulation of TGF- $\beta$ signal transduction. Scientifica 2014:874065

67. Varga J, Abraham D (2007) Systemic sclerosis: a prototypic multisystem fibrotic disorder. J Clin Investig 117:557-567

68. Guilluy C, Sauzeau V, Rolli-Derkinderen M, Guérin P, Sagan C, Pacaud P, Loirand G (2005) Inhibition of RhoA/Rho kinase pathway is involved in the beneficial effect of sildenafil on pulmonary hypertension. Br J Pharmacol 146:1010-1018

69. Zenzmaier C, Kern J, Sampson N, Heitz M, Plas E, Untergasser G, Berger P (2012) Phosphodiesterase type 5 inhibition reverts prostate fibroblast-to-myofibroblast trans-differentiation. Endocrinology 153:5546-5555 
70. Vignozzi L, Gacci M, Cellai I, Morelli A, Maneschi E, Comeglio P, Santi R, Filippi S, Sebastianelli A, Nesi G, Serni S, Carini M, Maggi M (2013) PDE5 inhibitors blunt inflammation in human BPH: a potential mechanism of action for PDE5 inhibitors in LUTS. Prostate 73:1391-1402

71. Bella AJ, Deyoung LX, Al-Numi M, Brock GB (2007) Daily administration of phosphodiesterase type 5 inhibitors for urological and nonurological indications. Eur Urol 52:990-1005

72. Fries R, Shariat K, von Wilmowsky H, Böhm M (2005) Sildenafil in the treatment of Raynaud's phenomenon resistant to vasodilatory therapy. Circulation 112:2980-2985

73. Takeda N, Manabe I (2011) Cellular interplay between cardiomyocytes and nonmyocytes in cardiac remodeling. Int J Inflamm 2011:535241

74. Ross RS (2004) Molecular and mechanical synergy: cross-talk between integrins and growth factor receptors. Cardiovasc Res 63:381-390

75. Sottili M, Cosmi L, Borgogni E, Sarchielli E, Maggi L, Francalanci M, Vannelli GB, Ronconi E, Adorini L, Annunziato F, Romagnani P, Serio M, Crescioli C (2009) Immunomodulatory effects of BXL-01-0029, a less hypercalcemic vitamin D analogue, in human cardiomyocytes and T cells. Exp Cell Res 315:264-273

76. Crescioli C, Squecco R, Cosmi L, Sottili M, Gelmini S, Borgogni E, Sarchielli E, Scolletta S, Francini F, Annunziato F, Vannelli GB, Serio M (2008) Immunosuppression in cardiac graft rejection: a human in vitro model to study the potential use of new immunomodulatory drugs. Exp Cell Res 314:1337-1350

77. Ridker PM, Cushman M, Stampfer MJ, Tracy RP, Hennekens CH (1997) Inflammation, aspirin, and the risk of cardiovascular disease in apparently healty men. N Engl J Med 336:973-979

78. Romagnani P, Crescioli C (2012) CXCL10: a candidate biomarker in transplantation. Clin Chim Acta 413:1364-1373

79. Crescioli $\mathrm{C}$ (2013) The role of immunological biomarkers in cardiac rejection. Curr Opin Organ Transplant 18:595-600

80. Scolletta S, Colletti M, Di Luigi L, Crescioli C (2013) Vitamin D receptor agonists target CXCL10: new therapeutic tools for resolution of inflammation. Med Inflamm 2013:876319

81. Penna G, Fibbi B, Amuchastegui S, Cossetti C, Aquilano F, Laverny G, Gacci M, Crescioli C, Maggi M, Adorini L (2009) Human benign prostatic hyperplasia stromal cells as inducers and targets of chronic immuno-mediated inflammation. J Immunol 182:4056-4064

82. Bonecchi R, Bianchi G, Bordignon PP, D’Ambrosio D, Lang R, Borsatti A, Sozzani S, Allavena P, Gray PA, Mantovani A, Sinigaglia F (1998) Differential expression of chemokine receptors and chemotactic responsiveness of type $1 \mathrm{~T}$ helper cells (Th1s) and Th2s. J Exp Med 187:129-134

83. Hancock WW, Gao W, Csizmadia V, Faia KL, Shemmeri N, Luster AD (2001) Donor-derived IP-10 initiates development of acute allograft rejection. J Exp Med 193:975-980

84. Crescioli C, Buonamano A, Scolletta S, Sottili M, Francalanci M, Giomarelli P, Biagioli B, Lisi G, Pradella F, Serio M, Romagnani P, Maccherini M (2009) Predictive role of pretransplant serum CXCL10 for cardiac acute rejection. Transplant 87:249-255
85. Yue Y, Gui J, Ai W, Xu W, Xiong S (2011) Direct gene transfer with IP-10 mutant ameliorates mouse CVB3-induced myocarditis by blunting Th1 immune responses. PLoS One 6:e18186

86. Scolletta S, Buonamano A, Sottili M, Giomarelli P, Biagioli B, Vannelli GB, Serio M, Romagnani P, Crescioli C (2012) CXCL10 release in cardiopulmonary bypass: an in vivo and in vitro study. Biomed and Agin Pathol 2:187-194

87. van den Borne P, Quax PHA, Hoefer IE, Pasterkamp G (2014) The multifaceted functions of CXCL10 in cardiovascular disease. BioMed Res Int 2014:893106

88. Salari P, Abdollahi M (2012) Phosphodiesterase inhibitors in inflammatory bowel disease. Expert Opin Investig Drugs 21:261-264

89. Zhuang XD, Long M, Li F, Hu X, Liao XX, Du ZM (2014) PDE5 inhibitor sildenafil in the treatment of heart failure: a meta-analysis of randomized controlled trials. Int $\mathrm{J}$ Cardiol 172:581-587

90. Redfield MM, Borlaug BA, Lewis GD, Mohammed SF, Semigran MJ, Lewinter MM, Deswal A, Hernandez AF, Lee KL, Braunwald E, Network The Heart Failure Clinical Research (2012) Phosphdiesterase-5 inhibition to improve clinical status and exercise capacity in diastolic heart failure (RELAX) trial: rationale and design. Circ Heart Fail 5:653-659

91. Degen CV, Bishu K, Zakeri R, Ogut O, Redfield MM, Brozovich FV (2015) The emperor's new clothes: PDE5 and the heart. PLoS One 10:e0118664

92. Takimoto E, Champion HC, Li M, Belardi D, Ren S, Rodriguez ER, Bedja D, Gabrielson KL, Wang Y, Kass DA (2005) Chronic inhibition of cyclic gmp phosphodiesterase 5a prevents and reverses cardiac hypertrophy. Nat Med 11:214-222

93. Nagendran J, Archer SL, Soliman D, Gurtu V, Moudgil R, Haromy A, St Aubin C, Webster L, Rebeyka IM, Ross DB, Light PE, Dyck JR, Michelakis ED (2007) Phosphodiesterase type 5 is highly expressed in the hypertrophied human right ventricle, and acute inhibition of phosphodiesterase type 5 improves contractility. Circulation 116:238-248

94. Shan X, Quaile MP, Monk JK, French B, Cappola TP, Margulies KB (2012) Differential expression of pde5 in failing and nonfailing human myocardium. Circ Heart Fail 5:79-86

95. Pokreisz P, Vandenwijngaert S, Bito V, Van den Bergh A, Lenaerts I, Busch C, Marsboom G, Gheysens O, Vermeersch P, Biesmans L, Liu X, Gillijns H, Pellens M, Van Lommel A, Buys E, Schoonjans L, Vanhaecke J, Verbeken E, Sipido K, Herijgers P, Bloch KD, Janssens SP (2009) Ventricular phosphodiesterase-5 expression is increased in patients with advanced heart failure and contributes to adverse ventricular remodeling after myocardial infarction in mice. Circulation 119:408-416

96. Lu Z, Xu X, Hu X, Lee S, Traverse JH, Zhu G, Fassett J, Tao Y, Zhang P, dos Remedios C, Pritzker M, Hall JL, Garry DJ, Chen Y (2010) Oxidative stress regulates left ventricular pde5 expression in the failing heart. Circulation 121:1474-1483

97. Borlaug BA, Paulus WJ (2011) Heart failure with preserved ejection fraction: pathophysiology, diagnosis, and treatment. Eur Heart J 32:670-679 